\title{
Reflective Learning in Higher Education: Active Methodologies for Transformative Practices
}

\author{
Jordi Colomer ${ }^{1,2, *(\mathbb{D}}$, Teresa Serra ${ }^{1}$, Dolors Cañabate ${ }^{2,3}$ and Remigijus Bubnys ${ }^{4}$ (D) \\ 1 Department of Physics, University of Girona, 17003 Girona, Spain; teresa.serra@udg.edu \\ 2 Teaching Innovation Networks on Reflective and Cooperative Learning, Institute of Sciences Education, \\ University of Girona, 17003 Girona, Spain; dolors.canyabate@udg.edu \\ 3 Department of Specific Didactics, University of Girona, 17004 Girona, Spain \\ 4 Panevežys Faculty of Technologies and Business, Technologies and Entrepreneurship Competences Centre, \\ Kaunas University of Technology, 37164 Panevežys, Lithuania; remigijus.bubnys@ktu.lt \\ * Correspondence: jordi.colomer@udg.edu; Tel.: +34-630-349-766
}

Received: 7 April 2020; Accepted: 28 April 2020; Published: 8 May 2020

check for updates

\begin{abstract}
In this Special Issue, Reflective Learning in Higher Education explores on tertiary education and its practices. It looks at in-house and external individuals, and collective initiatives and activities that centre on generating and reflecting on knowledge. It also explores the transformation output of learning communities, the communities themselves and their reflective practices, and discusses how reflective learning and developing one's professional identity through reflection are linked. The connections between the theoretical and applied research on reflective practices, knowledge generation in all areas, professional practice and identity through theoretical definition, situated and grounded practice and transformative knowledge are also considered. The nine manuscripts in this Special Issue manifest that reflective learning is likely to (i) help forge students' professional identity and ensure sustainable competences are effectively developed, (ii) transform students' preconceived perspectives and social preferences to foster new reasoned action plans for decision-making, (iii) promote understanding one's personal professional strengths and limitations and develop the ability to identify resources and ways to solve existing and/or future professional challenges and (iv) modify the students' beliefs, attitudes, and daily behaviour to develop competences that will ultimately result in promoting sustainability.
\end{abstract}

Keywords: reflective learning; pedagogical approach; transformative education; tertiary systems; sustainability

\section{Introduction}

Sustainable development is described by the United Nations Economic Commission for Europe (UNECE)'s Strategy for Education for Sustainable Development (ESD) as being underpinned by an ethic of solidarity, equality, and mutual respect among people, countries, cultures and generations. ESD is development in harmony with nature and meeting the needs of the present generation without compromising the ability of future generations to meet their own needs [1]. It empowers people to change their way of thinking and to work towards a sustainable future. Knowledge, skills, and attitudes to managing sustainable development are under the spotlight in all types of education because they are needed for future agents in the field of sustainable development [2,3]. ESD aims to develop competences that enable and empower individuals to reflect on their own actions by taking into account their current and future social, cultural, economic and environmental issues. ESD is designed for local and global perspectives, acts in complex situations in a sustainable manner-which 
may require the individual to strike out in new directions-and participates in socio-political processes moving societies towards sustainable development.

The global challenges facing contemporary society call for viable strategies and prompt action to address individual and collective issues and challenges, as well as their approaches to tackling them. To do so requires observing and understanding the viewpoint and complexity of the educational systems; as represented in the United Nations 2016 Sustainable Development Goals (SDGs) to be achieved in 2030. However, less than one decade remains in which to establish and facilitate education frameworks for citizenship awareness and participation, and develop new ways of knowledge production and decision-making with respect to sustainability. Efforts should be channelled towards (i) validating different didactic strategies and approaches to address sustainability from a constructivist and pedagogical community [4], (ii) diagnosing the status of sustainability training needs for formal and/or non-formal education, (iii) identifying the sustainability competence levels of children and young people currently in educational centres across the board and (iv) developing and testing appropriate and effective educational activities and practices [5]. While a few studies have investigated the pedagogical approaches and their effects on sustainable competences [6-8], the research, however, still remains limited.

The process of education is characterised by cognitive contemplation, learning to manage processes through skills and active experimenting [4,6]. It is an individual process where students expand their knowledge and understanding, their skills and experiences, values and attitudes and develop these into social values [9-12]. This is an interactive process in which the students, as learners, examine their experiences, reflect on them through spontaneous or routine activities, discover and subconsciously construe new meanings and insights, and foresee new perspectives [11]; it is the process of integrating the previously available knowledge with the new, by putting their theoretical knowledge into practice $[9,12]$. Independent of what formal knowledge is provided in the education process, each student will model original understanding of the phenomenon or activities and will create and build their own theories to final understanding. Reflective learning, then, allows for students' personal growth to be observed and helps to foresee ways of developing teaching processes to encourage learning in, for instance, higher education institutions, among others [13,14].

Professional development is a person's capacity to continuously learn through their ability to reflect, to analyse their experiences in depth, to develop and substantiate knowledge, and to refresh and revaluate it. All this is in order to better know and manage themselves by diagnosing personal mistakes, and acquiring and developing efficient analytical skills for learning and about learning, through learning [13]. Reflection is directly linked with a practitioner's motivation for conscious activities, their modelling and adjustment; it indirectly determines the practitioner's empowerment for constant learning/development by assuming responsibility for their own actions and solutions [15-17]. The process of reflective learning is characterised by a transformative empowering of students for personal, unrestricted, independent activity by (i) analysing their own experiences and learning skills, (ii) relating theoretical knowledge to practical knowledge and developing skills to identify and solve problems and (iii) changing their attitudes and becoming more tolerant $[18,19]$.

When reflection (as a component of reflective learning), deliberates on acquired experience, diagnosing one's own mistakes and learning from detailed analysis, only then does an open possibility for reform emerge from the professional experience which employs reflective thinking and refers to one's personal system of viewpoints, attitudes and values [20,21]. Reflection-as the premise of the educational transformation of experience for learning at primary, secondary and tertiary institutions-depends on the conditions provided for it. Conditions for reflective teaching and learning are created by developing the learner's competence to reflect, where individual experiences, thoughts, emotions and actions become the essential elements embedded in the ability to recognise the social and political contexts in which the individual lives and the values they want to keep to be inclusive, democratic, sustainable and social $[22,23]$. 


\section{Conceptual Contributions}

In this Special Issue, two papers focus on developing conceptual models. In Contribution 1, Calvo and colleagues present a theoretical framework developed by Wingate to evaluate a curriculum-integrated inclusive practice intervention in the United Kingdom with students from a first-year credit-bearing module at a tertiary institution. The study uses a mixed-methods approach that includes a literature review, secondary data, a feedback questionnaire and a focus group to evaluate a teaching method and reflect on the collaboration of the team members. The team teaching the module and the students taking it, considered the intervention as positive, welcoming and often crucial for supporting undergraduate students into the disciplinary discourse of their subject of study. Recommendations were made to develop better guidelines on how to deliver the integrated academic literacy as well as the importance of student participation, student learning assistants and graduate teaching assistants, in the design of the intervention. The study contributes to the literature on inclusive practice intervention and pedagogical approaches to integrating academic literacy into subject teaching for a diverse student population, thus contributing to the social sustainability of universities.

In Contribution 2, Gómez-Barreto, Merino-Tejedor and Sánchez-Santamaría prove that higher-order thinking skills are recognised as influential attributes to be considered for quality learning in pre-service teachers. Using an adapted tool based on Ritchhart's scale [24] with eight scales of cultural forces assessment, over 700 pre-service teachers identified pupils' prime-valued skills as being interactions, expectations, environment, language and time, as well as others like the development of thinking skills, modelling, opportunities to think and thinking routines. These dimensions are highly useful instruments for professors to obtain accurate feedback on how students perceive that learning-process mediation emphasizes the promotion of thought. The analysis of the dimensions may provide lecturers with information on how to facilitate reflection on teaching action(s) and (as teachers need evidence that makes them aware of the importance of promoting routines and situations linked to reflective thinking) how to optimise educational quality. In Contribution 8, Alsina and Mulà begin to characterise the elements of teacher educators' professional practice that promote the transformation of prior knowledge, experiences, and system beliefs into professional competences, based on reflective learning and education for sustainability. To obtain data, they analysed 30 class sessions given by a mathematics teacher. Five elements of the teacher's practice were identified: (1) presents real action, (2) uncovers students' values and preconceptions and takes them into consideration, (3) systematises these values and preconceptions and contrasts them with the 'ideal', (4) helps the learners to understand the perspective offered by mathematical and sustainability concepts and (5) helps the students develop a new perspective acquired through grounded and reasoned action plans. A key conclusion of the study is that it is prior knowledge, experiences, and beliefs which are transformed if the two agents involved in the learning process (pre-service teachers and university lecturers) are synchronised.

\section{Transforming Learning through Active Methodologies}

Contribution 3 by Cañabate, Serra, Bubnys and Colomer, focuses on how reflective learning, when operated together with cooperative learning, may foster and enhance the professional identity of tertiary students studying to be teachers. In this study, pre-service teachers were involved in reflection-in-action and reflection-on-action in order to contemplate their professional identity. The students' reflections were firstly analysed from the pre-service teachers' reflective narratives that included the focus of the reflection, awareness of previous beliefs, knowledge, and experiences, inquiring into and focusing on possible actions through questions and hypotheses, and arguing for concrete learning objectives. Then, they were analysed through the pre-service teachers' professional identity, including self-esteem, task perception, job motivation, and expectations about future jobs. The results from the instructional cooperative approaches based on the reflections on the in-practice activities carried out at a primary school, disclosed the differences between them, with non-structured approaches scoring higher than structured ones. The cooperative challenges, when embedded in the reflection process, profoundly 
helped pre-service teachers to identify aspects of their professional identity that may ensure an effective intake of sustainable competences.

In Contribution 4, Beranič and Heričko postulate that in order to achieve the best possible learning outcomes, it is advisable to implement learning approaches that require students' active participation, for example, an experiential learning approach. In their pedagogical proposal, introducing enterprise resource planning (ERP) concepts to IT students entailed many challenges. Due to the system's complexity, newcomers need an extensive amount of time to be able to use it independently. The authors implemented a game in sequential rounds, whereby each round ended with a review of the collected experiences. The simulation game was used at the beginning of the course to assist with the introduction of ERP concepts. Perceived usability was measured using a System Usability Scale (SUS), while the students' experiences were gathered using a self-evaluation questionnaire. The study revealed the positive impact the experiential learning approach had. Students evaluated the usability of SAP ERP as OK, and empirical analysis confirmed that using the simulation game to introduce the ERP concepts resulted not only in anticipated knowledge and skills, but it also increased the students' intent for future engagement.

In Contribution 7, Rodrigo-González, Caballer-Tarazona, and García-Gallego propose a teaching activity aimed at promoting social values, such as trust and reciprocity, among undergraduate students in Economics and related degrees. They present the Reading-Experiment-Discussion experience, a three-step activity as part of a class of a specific module at a Spanish tertiary institution. During the Reading step, the authors encouraged the students to reflect, learn, and think critically about social values. In the second step, Experiment, students made decisions in a trust game experiment in which a game created to measure trust and reciprocity in economic environments was used. Students then gave opinions through a post-experiment questionnaire. They also investigated the association between students' decisions and their attitudinal and sociodemographic characteristics by linear regression analysis. Experimental data showed that decisions on trust and reciprocity are dependent on earnings information and that, on average, females trust more than males. Finally, in the Discussion step, the learning was reinforced by sharing the readings about morals and the experimental decisions. In short, the pedagogical approach might greatly help to transmit to students the role social preferences play in the individual decision-making process.

In Contribution 9, Bubnys deals with experiential reflections of university students studying in a Bachelor of Special Education degree study program in a Lithuanian tertiary institution. The special educator was a teacher of children with special educational needs, i.e., an educational assistance specialist who is able to recognize, assess, and meet children's special educational needs arising from disabilities, disorders or learning difficulties, and to professionally provide special pedagogical assistance for inclusive and special education. To analyse the experience of prospective special educators who study at the university for four years, first year students were chosen. In the first month of their studies at the university, the first-year students did their teaching practice in institutions within the education system: pre-school, general and/or special education institutions. The aim of the practice was to become familiar with the subtleties of their future professional activity. The initial experience students had at the start of their studies was found to be important and significant for further studies at the university. The manuscript deals with the results of the written reflections of students who had returned from the practice. The phenomenological hermeneutics method revealed the students' experiences in their practical activities during their observational practice provided the students with a deeper understanding of their area of study and, through the (self) education process, a precondition for reflective learning in further university studies. The manuscript presents future special educators with practical experiences and perceptions of their roles in the profession. The results reveal that self-reflection provides students with a deeper perception of themselves as people with special educators' needs and problems, personal strengths and competence limitations that then enabled them to identify sources and means for solving existing and future professional activity problems. It further reveals that cooperation with family members, university teachers, social 
pedagogues, teachers, children with special educational needs, and sharing experiences with student colleagues can lead to greater self-confidence in oneself as a future specialist. Curiosity and personal initiative enabled students to identify the positive and difficult moments of their professional activity and future professional roles while learning from experience.

\section{Applied Research on Reflective Practices}

In Contribution 5, Grant, Gilgen, and Buchmann present the World Food System Summer School-an innovative two-week course seeking to develop the knowledge, skills and attitudes of the next generation of decision-makers to build sustainable food systems. Meaningful learning, where the participant was able to relate new information to existing knowledge, is a critical part of education about complex systems and requires the integration of reflective approaches to teaching and learning. Grant, Gilgen, and Buchmann adopted the rich picture method for three summer schools in Switzerland, South Africa and Côte d'Ivoire (74 participants with 29 nationalities) to support participant reflection on their knowledge acquired about complex food systems. Coding and comparing 51 pairs of pre- and post-course pictures of food systems clearly demonstrated newly gained knowledge as the number of sub-categories being significantly drawn increased from 11 to 19 in the post-course pictures. Interestingly, the largest increase occurred for environmental sustainability (57\%). The rich picture method is a highly valuable, simple tool with which to gain insight into how participants' knowledge changes and identify where the gaps in meeting the learning objectives are. This was particularly useful within a highly diverse participant cohort, as it allowed participants to discuss and reflect on their own learning experience in a personalised way. Additionally, the rich picture method provided insights for faculty to improve their approaches to teaching on food systems.

In Contribution 6, Díaz-Iso, Eizaguirre, and García-Olalla describe the integration of reflective learning to contribute to developing a greater awareness among individuals of the importance of facing the 21st century's sustainability challenges. This paper analysed the impact an extracurricular volunteer activity in Tangier, Morocco had on the development of student reflection at a Spanish university. The objectives of this study were first to explore students' primary reflections on the experience and second to analyse students' perceptions concerning the importance of participating in the experience in order to develop reflective learning. In-depth interviews were conducted with 23 students who participated in the volunteer activity. Data analysis was carried out to conduct a descending hierarchical classification (DHC) and a constant comparison analysis. This research highlighted the value that voluntary extracurricular activities have in developing reflections which then guided changes in the beliefs, attitudes, and daily behaviour of students and ultimately resulted in sustainability. Thanks to this, not only was it considered essential that students participated in social projects, but also that they undertook these with peers and instructors who could create environments of support and trust.

\section{Discussion and Conclusions}

Reflection is recognised as one of the most important transferable competences in lifelong learning and affects continuous personal and professional development. Reflective learning is becoming increasingly relevant to meet the challenges of a technologically advanced world and to develop the ability to adjust to ever-changing environments. As reflection allows for contemplation about new experiences and their association with past experiences in different contexts and focuses on future transformations, it offers ways in which, through active methodologies, reflective learning can change a person's awareness and ability to act in different contexts. As pointed out by Greig and Priddle [25], the Sustainable Development Goals require that, in the coming years, all learners should acquire the appropriate knowledge and skills to promote sustainable development. This objective demands the applicability of transformative interdisciplinary approaches, oriented to promoting (in addition to subject knowledge) sustainability as an explicit outcome. According to these authors, the complex nature of sustainability challenges indicates the need for learning experiences that emphasise active, 
reflective learning across and between discipline areas [25]. Reflective learning enables learners to improve their thinking, which leads to better actions towards well-being over time. Through reflection, learners gain a sense of power over their future actions-and a sense of direction-leading to the development of agency. Reflective learning results in a growing awareness of one's self, others and society at large. Developing reflective and critical competences are key objectives for tertiary educators, who need to adapt to an ever-evolving curriculum and to changing techniques and social environments.

For educators: Educators' tasks in the inclusive classroom include giving careful consideration to what is to be taught and how it is to be taught (rather than who is to learn), considering the learning needs of all children and young people (not just those with additional needs), questioning beliefs and rejecting deterministic and associated ideas, reflecting on daily life situations, constantly seeking out and trying new things to support all learners, discussing new initiatives with colleagues in order to receive feedback, examining, framing and attempting to solve dilemmas during activities, using journals to track individuals' learning, and taking responsibility for their own professional growth and understanding [26]. Reflective practices focus on students who may have behavioural, emotional and/or social difficulties which hamper their engagement as a learner and create personalised learning pathways. It prompts individual-centred reflection on how to increase the learner's engagement and thus leads to deep learning outcomes.

For students: The practice of reflective experiences acquired through active reflective methodologies can help to change formal learning habits and improve students' learning outcomes, as metacognitive skills developed through reflection are identified as one of the most important factors influencing learning $[9,27]$. The process of reflective learning is directed towards analysing and thinking over one's activity, inner self-feeling, attitudes, feelings, and empathies. This is not just knowledge and self-perception but also finding out how others see you. Inner reflection is directed to personal activity, ideas and feelings. Outer reflection is directed towards processes, and events related to the external world. Students, when placed in active reflective practices, develop higher cognitive processes and trigger individual activities with a focus on finding problems and solutions, comparison and contrapositions, statement and confirmations, aim, action and result [28].

\section{List of Contributions}

1. Calvo, S.; Celini, L.; Morales, A.; Martínez, J.M.G.; Núñez-Cacho Utrilla, P. Academic Literacy and Student Diversity: Evaluating a Curriculum-Integrated Inclusive Practice Intervention in the United Kingdom. Sustainability 2020, 12, 1155.

2. Gómez-Barreto, I.M.; Merino-Tejedor, E.; Sánchez-Santamaría, J. University Students' Perspectives on Reflective Learning: Psychometric Properties of the Eight-Cultural-Forces Scale. Sustainability 2020, 12, 729 .

3. Cañabate, D.; Serra, T.; Bubnys, R.; Colomer, J. Pre-Service Teachers' Reflections on Cooperative Learning: Instructional Approaches and Identity Construction. Sustainability 2019, 11, 5970.

4. Beranič, T.; Heričko, M. Introducing ERP Concepts to IT Students Using an Experiential Learning Approach with an Emphasis on Reflection. Sustainability 2019, 11, 4992.

5. Grant, M.; Gilgen, A.K.; Buchmann, N. The Rich Picture Method: A Simple Tool for Reflective Teaching and Learning about Sustainable Food Systems. Sustainability 2019, 11, 4815.

6. Díaz-Iso, A.; Eizaguirre, A.; García-Olalla, A. Extracurricular Activities in Higher Education and the Promotion of Reflective Learning for Sustainability. Sustainability 2019, 11, 4521.

7. Rodrigo-González, A.; Caballer-Tarazona, M.; García-Gallego, A. Active Learning on Trust and Reciprocity for Undergraduates. Sustainability 2019, 11, 4399.

8. Alsina, Á.; Mulà, I. Advancing towards a Transformational Professional Competence Model through Reflective Learning and Sustainability: The Case of Mathematics Teacher Education. Sustainability 2019, 11, 4039. 
9. Bubnys, R. A Journey of Self-Reflection in Students' Perception of Practice and Roles in the Profession. Sustainability 2019, 11, 194.

Author Contributions: Conceptualization, J.C.; validation, T.S. and D.C.; writing—original draft preparation, J.C. and R.B.; writing - review and editing, J.C. and T.S.; supervision, R.B. and D.C.; funding acquisition, J.C. and D.C. All authors have read and agreed to the published version of the manuscript.

Funding: This research was funded by the Institute of Sciences Education Josep Pallach, University of Girona, grant number XIDAR-19/20.

Conflicts of Interest: The authors declare no conflict of interest. The funders had no role in the design of the study; in the collection, analyses, or interpretation of data; in the writing of the manuscript, and in the decision to publish the results.

\section{References}

1. UNECE. Empowering Educators for a Sustainable future. In Tools for Policy and Practice Workshops on Competences in Education for Sustainable Development; United Nations EC/CEP/: Geneva, Switzerland, 2013; Volume 165, pp. 14-15.

2. Rieckmann, M. Chapter 2-Learning to transform the world: Key competencies in ESD. In Issues and Trends in Education for Sustainable Development; Leicht, A., Heiss, J., Byun, W.J., Eds.; UNESCO: Paris, France, 2018; pp. 39-59.

3. Fuertes-Camacho, M.T.; Graell-Martín, M.; Fuentes-Loss, M.; Balaguer-Fàbregas, M.C. Integrating Sustainability into Higher Education Curricula through the Project Method, a Global Learning Strategy. Sustainability 2019, 11, 767. [CrossRef]

4. Lozano, R.; Merrill, M.Y.; Sammalisto, K.; Ceulemans, K.; Lozano, F.J. Connecting Competences and Pedagogical Approaches for Sustainable Development in Higher Education: A Literature Review and Framework Proposal. Sustainability 2017, 9, 1889. [CrossRef]

5. Tejedor, G.; Segalàs, J.; Barrón, A.; Fernández-Morilla, M.; Fuertes, M.T.; Ruiz-Morales, J.; Gutiérrez, I.; García-González, E.; Aramburuzabala, P.; Hernández, À. Didactic strategies to promote competencies in sustainability. Sustainability 2019, 11, 2086. [CrossRef]

6. Cañabate, D.; Serra, T.; Bubnys, R.; Colomer, J. Pre-Service Teachers' Reflections on Cooperative Learning: Instructional Approaches and Identity Construction. Sustainability 2019, 21, 5970. [CrossRef]

7. Guillén-Gámez, F.D.; Higueras-Rodríguez, L.; Medina-García, M. Developing a Regression Model of Cooperative Learning Methodology in Pre-Service Teacher Education: A Sustainable Path for Transition to Teaching Profession. Sustainability 2020, 12, 2215. [CrossRef]

8. Mendo Lázaro, S.; León Del Barco, B.; Polo-Del-Río, M.-I.; Rasskin-Gutman, I. Predictive Factors of Task Interdependence in the University Context. Sustainability 2020, 12, 100. [CrossRef]

9. Colomer, J.; Serra, L.; Cañabate, D.; Serra, T. Evaluating Knowledge and Assessment-Centered Reflective-Based Learning Approaches. Sustainability 2018, 10, 3122. [CrossRef]

10. Cañabate, D.; Nogué, L.; Serra, T.; Colomer, J. Supportive Peer Feedback in Tertiary Education: Analysis of Pre-service Teachers' Perceptions. Educ. Sci. 2019, 9, 280. [CrossRef]

11. Bubnys, R. A Journey of Self-Reflection in Students' Perception of Practice and Roles in the Profession. Sustainability 2019, 11, 194. [CrossRef]

12. Cañabate, D.; Martínez, G.; Rodríguez, D.; Colomer, J. Analysing Emotions and Social Skills in Physical Education. Sustainability 2018, 10, 1585. [CrossRef]

13. Körkkö, M.; Krö-Ämmälä, O.; Turunen, T. Professional development through reflection in teacher education. Teach. Teach. Educ. 2016, 55, 198-206. [CrossRef]

14. Fullana, J.; Pallisera, M.; Colomer, J.; Fernandez-Peña, R.; Perez-Burriel, M. Reflective learning in higher education: A qualitative study on students' perceptions. Stud. High. Educ. 2016, 41, 1008-1022. [CrossRef]

15. Yuan, R.; Mak, P. Reflective learning and identity construction in practice, discourse and activity: Experiences of pre-service language teachers in Hong Kong. Teach. Teach. Educ. 2018, 74, 205-214. [CrossRef]

16. Ryan, M.; Carmichael, M. Shaping (reflexive) professional identities across an undergraduate degree programme: A longitudinal case study. Teach. High. Educ. 2015, 21, 151-165. [CrossRef] 
17. Ryan, M.E. Introduction: Reflective and reflexive approaches in Higher Education: A warrant for lifelong learning. In Teaching Reflective Learning in Higher Education: A Systematic Approach Using Pedagogic Patterns; Ryan, M.E., Ed.; Springer: Sydney, Australia, 2014; pp. 3-14.

18. Larrivee, B. Transforming teaching practice: Becoming the critically reflective teacher. Reflective Pract. 2000, 1, 293-307. [CrossRef]

19. Loughran, J.J. Effective reflective practice: In search of meaning in learning about teaching. J. Teach. Educ. 2002, 53, 33-43. [CrossRef]

20. Alsina, A.; Ayllón, S.; Colomer, J. Validating the narrative reflection assessment rubric (NARRA) for reflective narratives in higher education. Assess. Eval. High. Educ. 2019, 44, 155-168. [CrossRef]

21. Alsina, Á.; Ayllón, S.; Colomer, J.; Fernández-Peña, R.; Fullana, J.; Pallisera, M.; Pérez-Burriel, M.; Serra, L. Improving and evaluating reflective narratives: A rubric for higher education students. Teach. Teach. Educ. 2017, 63, 148-158. [CrossRef]

22. Panadero, E.; Jonsson, A.; Botella, J. Effects of self-assessment on self-regulated learning and self-efficacy: Four meta-analyses. Educ. Res. Rev. 2017, 22, 74-98. [CrossRef]

23. Ayllón, S.; Alsina, Á.; Colomer, J. Teachers 'involvement and students' self-efficacy: Keys to achievement in higher education. PLoS ONE 2019, 14, e0216865. [CrossRef]

24. Ritchhart, R. Creating Cultures of Thinking. In The 8 Forces We Must Master to Truly Transform Our School; Jossey Bass: San Francisco, CA, USA, 2015.

25. Greig, A.; Priddle, J. Mapping Students' Development in Response to Sustainability Education: A Conceptual Model. Sustainability 2019, 11, 4324. [CrossRef]

26. Minott, M. Reflective teaching, inclusive teaching and the teacher's tasks in the inclusive classroom: A literary investigation. Br. J. Spec. Educ. 2019, 46, 226-238. [CrossRef]

27. Bryce, D.; Whitebread, D.; Szúcs, D. The relationships among executive functions, metacognitive skills and educational achievement in 5- and 7-year-old children. Metacognition Learn. 2014, 10, 181-198. [CrossRef]

28. Geleziniene, R. Reflective activities of pupils with special educational needs and teachers in the self-educational process. Soc. Welf. Interdiscip. Approach 2011, 1, 60-69. [CrossRef]

(C) 2020 by the authors. Licensee MDPI, Basel, Switzerland. This article is an open access article distributed under the terms and conditions of the Creative Commons Attribution (CC BY) license (http://creativecommons.org/licenses/by/4.0/). 